\title{
Performance Evaluation of CDMA - MIMO (STBC) System over Rayleigh Fading Channel for Image Transmission
}

\author{
I G. A. K. Diafari Djuni H. ${ }^{1^{*}}$, I G. A. P. Raka Agung ${ }^{2}$ \\ 1,2 Electrical Engineering Department \\ Faculty of Engineering, Udayana University \\ Denpasar, Indonesia \\ *igakdiafari@yahoo.com
}

\begin{abstract}
Data transmission via wireless communication system is not only in text form but it also can be in image form. In the process of sending data or information, it often experiences interference in transmission media, which is fading. The method used in this research is by simulation using MATLAB. The simulation of CDMA-MIMO (STBC) system with Walsh spreading code is expected to reduce the disturbance of fading. Fading channels can be modeled using Rayleigh distribution. The number of users and spreading factors affect the performance of CDMA-MIMO (STBC) systems. The parameters used in this simulation were SNR, BER, and PSNR. The results showed that image reconstruction passing CDMAMIMO system with spreading factor 4 has better image quality. Its PSNR 33.9589dB when SNR -10dB. SNR was increased $10 \mathrm{~dB}$ then PSNR $60.00 \mathrm{~dB}$. The increasing of spreading factor to 8 and 16 was obtained by increasing PSNR, PSNR 35.0685 dB and PSNR 37.5665 dB, respectively. For 4 users with Spreading Factor 4 and SNR 0 to $5 \mathrm{~dB}$, it was changed the BER. This is influenced by changes in SNR. The higher SNR value, the average value of BER will be smaller. A growing number of users from 1 to 4 users were decreased the performance of the MIMO CDMA system when observed from the BER and PSNR.
\end{abstract}

Index Terms - CDMA, MIMO, Rayleigh Fading, Image, Spreading Factor.

\section{INTRODUCTION}

Mobile radio technology has always evolved from analog technology used in the first generation $(1 \mathrm{G})$ and then developed to digital technology in the fourth generation (4G). One telecommunication technology is being implemented, CDMA. Code division Multiple Access (CDMA) is a form of multiplexing and a shared access method that divides the channel by encoding data with a special code and using the constructive interference properties of the special codes to perform multiplexing.

The radio wave propagation between the transmitter and the receiver will pass through different paths. With the different paths resulting in reflection (reflection), scattering, and diffraction on the signal is often referred to as fading. Rayleigh distribution is used to explain the shape of signal envelope on fading channel. One of which reducing the fading effect on the communication channel in telecommunication services is done by diversity technique or often called diversity. This diversity is known as MIMO (Multiple-Input Multiple-Output) system. In transmitter diversity requires a combination of space and time diversity through a technique called Alamouti space-time block codes (STBC) scheme. This system uses more than one transmit and receive antennas. It aims to make the reflected signal as the main signal amplifier so that mutual support or not eliminate each other

The purpose of this research is to know the effect of transmission Jpeg compressed digital image data on CDMA-MIMO system using Walsh spreading code on Rayleigh distributed fading channel with different spreading factor and number of users more than 1 user. The CDMA-MIMO system performance is seen from the relationship between the BER (bit-error-rate) and SNR (signal-to-noise-ratio) and PSNR (Peak Signal to Noise Ratio).

\section{RESEARCH METHODS}

In the performance of analyze of CDMA MIMO with the number of user from 1 to 4 user and Spreading Factor changed there are some things to be considered, so that the simulation can be done. Beginning with the literature understanding from various sources about system modeling. The design stage of the simulation program is based on the 
issues to be discussed, such as input data using JPG compressed digital image, system modulation, fading channel and CDMA MIMO system. MIMO used is MIMO STBC (Space Time Block Code) with maximum detection like hood. The system simulation with Matlab software version R2013a. A completed simulation program needs to be evaluated to avoid any deficiencies or errors. System performance reference used BER value (Bit Error Rate) and PSNR (Peak Signal to Noise Ratio). The performance parameters of CDMA MIMO system from simulation can be shown in table 1 .

TABLE I

SimUlation PARAMETER OF CDMA MIMO SYSTEM MODEL

\begin{tabular}{|l|l|}
\hline Parameter & Item \\
\hline User & 4 \\
\hline Image compressed & Jpg \\
\hline Image Resolution & $128 \times 128$ \\
\hline Spreading Factor & $4,8,16$ \\
\hline Modulation & QPSK \\
\hline Spreading Code & Walsh \\
\hline Channel & Rayleigh Fading and AWGN \\
\hline
\end{tabular}

Configuration of simulation block diagram of CDMA MIMO system performance with change of number of users ( 1 to 4 user) and Spreading Factor $=4$ can be seen in figure 1.

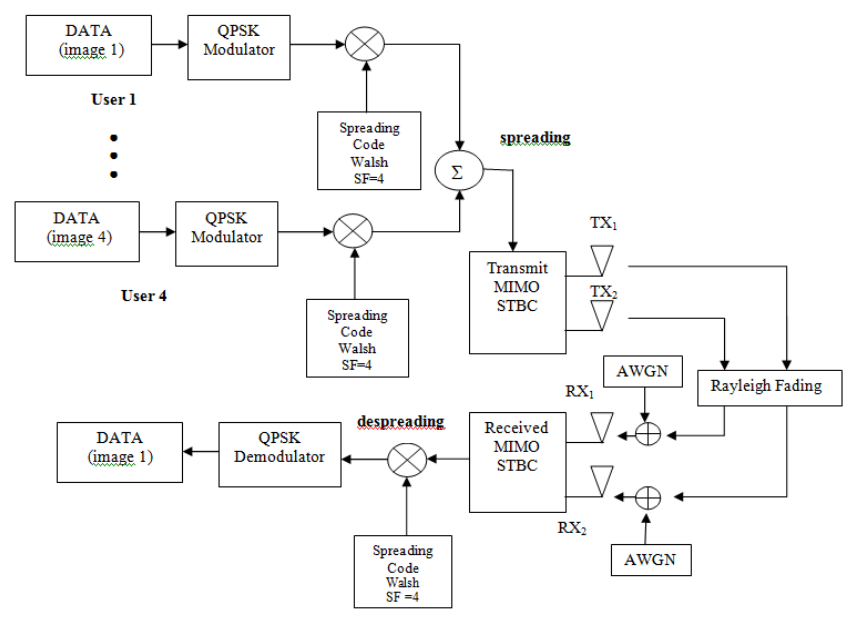

Fig. 1. Block diagram of CDMA MIMO system performance with 4 user and number Spreading Factor $=4$

\section{Simulation ReSUlts AND Discussion}

This section will describe the performance of CDMA MIMO (STBC) in transmitting data in jpg compressed image for Walsh spreading code over Rayleigh distributed fading channel seen from the value of BER and PSNR generated.

\section{A. CDMA MIMO Simulation with different Spreading} Factor

The result of simulation of CDMA MIMO system performance with 1 user number for Walsh Spreading code which vary Spreading Factor are 4, 8, and 16 on channel fading distributed Rayleigh with SNR starting from $-10 \mathrm{~dB}$, $5 \mathrm{~dB}$, until a maximum of $10 \mathrm{~dB}$ is performed up to 5 experiments to obtain the average BER shown in graphical form in figure 5.9. The system input is a digital image of cameraman.jpg with 128x128resolution that has been changed into bit form by using Matlab. Output from jpg compressed image with $128 \times 128$ resolution on CDMA MIMO system with 1 user for SNR of $-10 \mathrm{~dB}$ and $-5 \mathrm{~dB}$ with PSNR as reference of system performance shown in figure 2.

\begin{tabular}{|c|c|}
\hline $\begin{array}{c}\mathrm{SF}=4, \mathrm{SNR}=-10 \mathrm{~dB} \\
\mathrm{PSNR}=33.9589\end{array}$ & $\begin{array}{c}\mathrm{SF}=8, \mathrm{SNR}=-10 \mathrm{~dB} \\
\mathrm{PSNR}=35.0685\end{array}$ \\
\hline 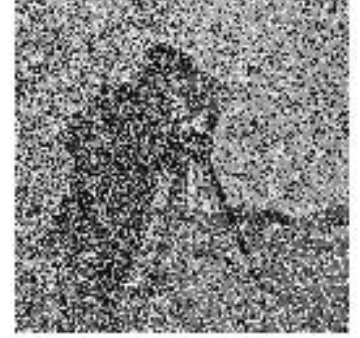 & 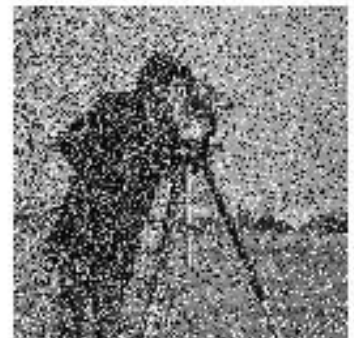 \\
\hline
\end{tabular}

\begin{tabular}{|c|c|}
\hline $\begin{array}{c}\mathrm{SF}=16, \mathrm{SNR}=-10 \mathrm{~dB} \\
\mathrm{PSNR}=37.5665\end{array}$ & $\begin{array}{c}\mathrm{SF}=4, \mathrm{SNR}=-5 \mathrm{~dB} \\
\mathrm{PSNR}=36.7313\end{array}$ \\
\hline & \\
\hline & \\
& \\
& \\
\end{tabular}

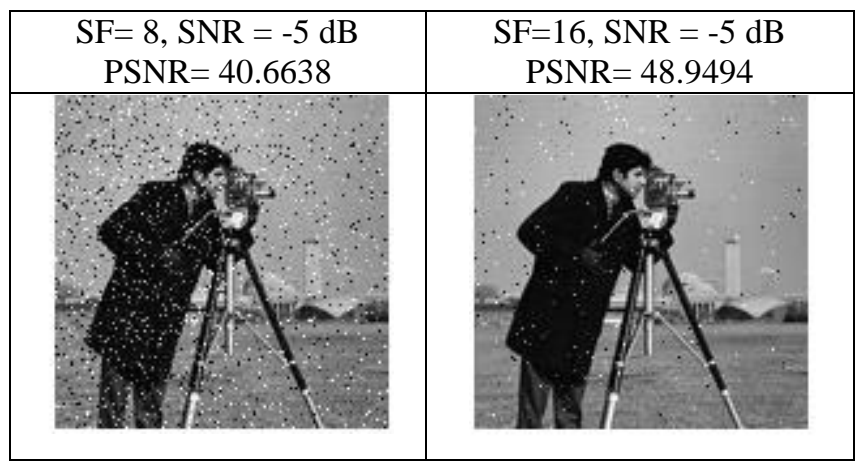

Fig.2. Output of the CDMA MIMO system for cameraman image with SNR $=-10 \mathrm{~dB}$ and $-5 \mathrm{~dB}$ 
Based on PSNR value for CDMA MIMO system with SNR of $-10 \mathrm{~dB}$ is $33.9589 \mathrm{~dB}$, with SNR addition being $-5 \mathrm{~dB}$ PSNR value of $36.7313 \mathrm{~dB}$. This shows that the result of image reconstruction passing through CDMA-MIMO system with SNR value addition has better quality. Performance improvements also occur in CDMA-MIMO systems using Spreading Factor $=8$ and 16 .

\section{B. CDMA MIMO Simulation with different User}

The performance simulation of CDMA MIMO system with jpg compressed image input for 4 users for Walsh and Spreading Factor $=4$ on Rayleigh distributed fading channel with SNR of $0 \mathrm{~dB}$ and $5 \mathrm{~dB}$ can be seen in Figure 3.

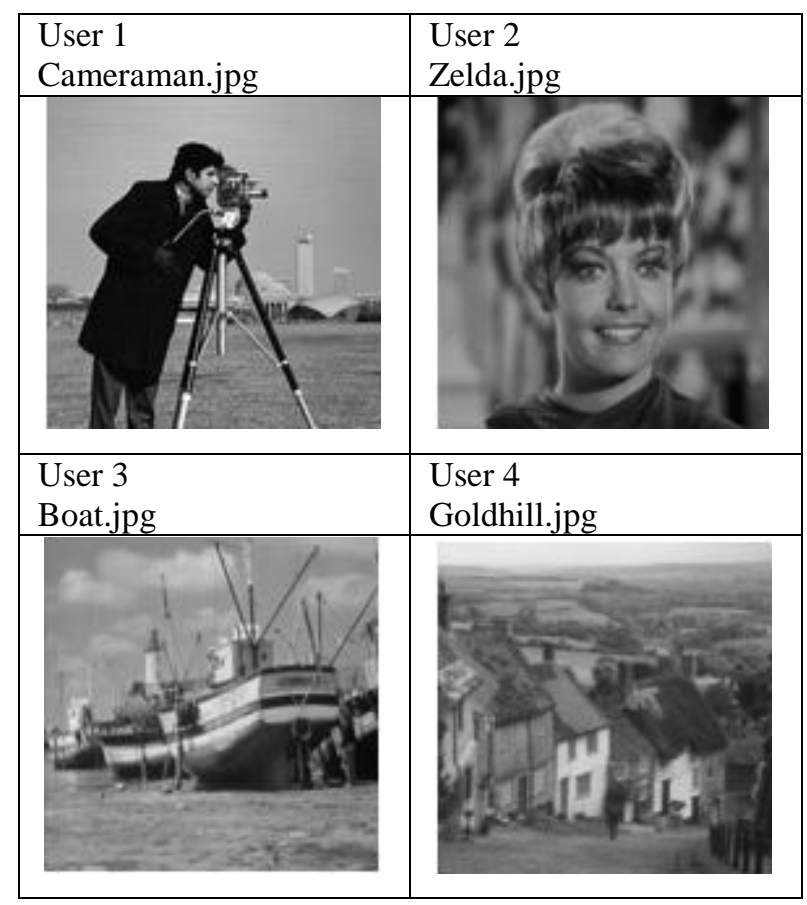

Fig 3. Compressed digital image with $128 \times 128$ resolution as CDMA MIMO system input for 4 user.

The output of the compressed image on the CDMA MMO system with the addition of the user for SNR of $0 \mathrm{~dB}$ and $5 \mathrm{~dB}$ is shown in figure 4 and figure 5.

\begin{tabular}{|l|l|}
\hline $\begin{array}{l}1 \text { user } \\
\text { SNR }=0 \mathrm{~dB} \\
\mathrm{BER}=0.01297 \\
\mathrm{PSNR}=45.6433\end{array}$ & $\begin{array}{l}\text { 2 user } \\
\text { SNR }=0 \mathrm{~dB} \\
\mathrm{BER}=0.06022 \\
\text { PSNR }=39.0189\end{array}$ \\
& \\
&
\end{tabular}

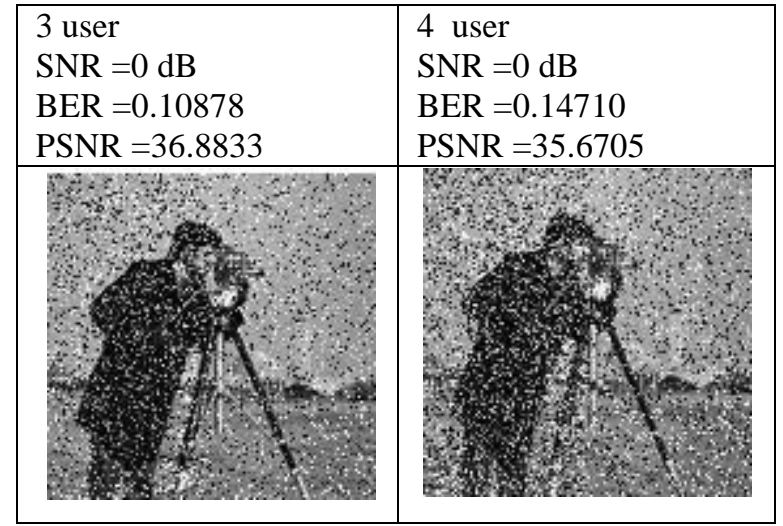

Fig 4. Output from CDMA MIMO system with different user for spreading factor $=4$ on SNR $=0 \mathrm{~dB}$

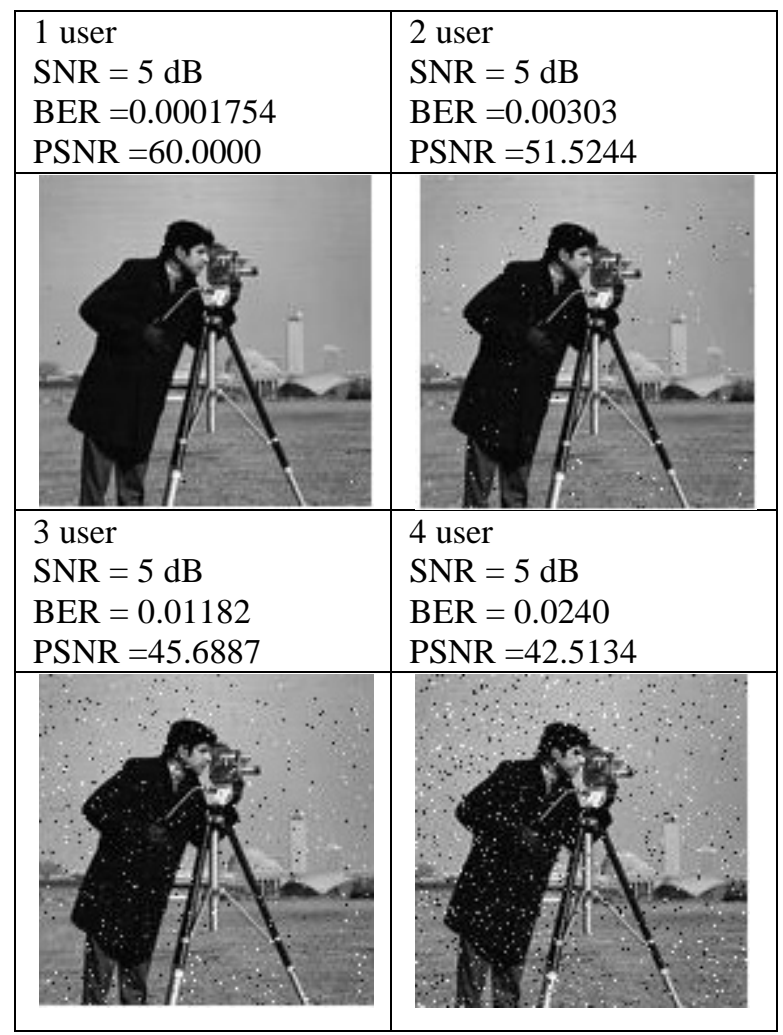

Fig 5. Output from CDMA MIMO system with different user for spreading factor $=4$ on $\mathrm{SNR}=5 \mathrm{~dB}$

PSNR value for CDMA MIMO system with SNR of $0 \mathrm{~dB}$ for 1 user is $45.6433 \mathrm{~dB}$. With the addition of the user to 4 , the PSNR value is $35.6705 \mathrm{~dB}$, then the maximum regulated SNR of $5 \mathrm{~dB}$ has a PSNR value of $60 \mathrm{~dB}$ if the number of users 1 , and the PSNR value decreases by $42.5134 \mathrm{~dB}$ for the addition of the user number of 4 users. This shows that the image reconnaissance that passes of the CDMA MIMO system with spreading factor 4, has a better quality when 1 user sends the image. The performance decline also occurs in the MIMO CDMA system which 4 users as shown in Figure 4. 


\section{CONCLUSION}

From the results of the analysis that has been done on the performance of CDMA MIMO system over Rayleigh fading channel for data transmission in the form of compressed image, it can be drawn some conclusions as follows,

1) Result of image reconstruction passing CDMA MIMO system with 2 transmitters and 2 receiver antennas have better image quality with PSNR of 33.9589dB when SNR -10dB, and SNR increased to maximum 10 $\mathrm{dB}$ will have PSNR $60.00 \mathrm{~dB}$ for spreading factor4. The increasing of spreading factor to 8 and 16 was increased PSNR, PSNR $35.0685 \mathrm{~dB}$ and PSNR $37.5665 \mathrm{~dB}$, respectively, SNR is $-10 \mathrm{~dB}$.

2) Performance of CDMA MIMO system with 4 users for Spreading Factor $=4$ and $\mathrm{SNR}=5 \mathrm{~dB}$ was experienced BER 0.0240 and PSNR 42.5134. The increasing number of users from 1 to 4 users was decreased system performance based on BER and PSNR parameters.

\section{ACKNOWLEDGMENT}

Acknowledgments addressed to Institute of Research and Community Service (LPPM) Udayana University and Faculty of Engineering Udayana University in Young Lecturer Research Grants Year 2016.

\section{REFERENCES}

[1] Alamouti, S. (1998). A Simple Transmit Diversity Technique for Wireless Communications, IEEE journal on selected areas in communications, vol. 16, no. 8, pp. 1451-1458, USA

[2] Anggaraini, R.,Baharuddin.,(2007.) Analisa Unjuk Kerja Quadrature Amplitude Modulation Pada Kanal Fading Untuk Citra Digital. Nov. 2007, Volume 1, No.28, Padang,.

[3] Chandra \& Chattopadhyay. 2009. Small Set Orthogonal Kasami Codes for CDMA. India. International Conference on Computers and Devices for Communication

[4] Glover, I. A. and Grant, P. M. (2004). Digital Communications, Prentice Hall, Inggris.

[5] Kostov, N. (2003). Mobile Radio Channel Modeling in Matlab. Department of Radio Engineering, Technical University of Varna, Bulgaria.

[6] Haryana \& Noida. 2010. Evaluation of Correlation Properties of Orthogonal Spreading Codes for CDMA Wireless Mobile Communication. India. IEEE 2nd International Advance Computing Conference.

[7] Meel, J., ir., 'Spread Spectrum', IWT HOBU Fonds, De NayerInstituut, October 1999

[8] Ngajikin, N., Nik Abdul Malik, N.N. ,Esa,M.R.M. and Idrus,S.M., Performance Analysis of MIMO-CDMA System, RF and Microwave Conference, 2006. RFM 2006. International , 12-14 Sept. 2006

[9] Proakis, John G. and Salehi, Masoud. (2000). Contemporary Communication system Using MATLAB, PWS, Northeastern University

[10] Samundiswary P and P.V.S.R.S ViswaKalyan, Performance Analysis of WCDMA using Different Spreading Codes ,International Journal of Computer Applications (0975 - 8887), Volume 38- No.10, January 2012 